\title{
Analisis Sentimen pada review Aplikasi Grab di Google Play Store Menggunakan Support Vector Machine
}

\author{
Rizki Wahyudi ${ }^{1}$, Gilang Kusumawardhana ${ }^{2}$ \\ ${ }^{1}$ Program Studi Informatika, Universitas Amikom Purwokerto \\ 2 Program Studi Sistem Informasi, Universitas Amikom Purwokerto \\ JI. Letjend Pol. Soemarto, Watumas, Purwanegara, Kec. Purwokerto Tim., Kabupaten Banyumas, \\ Jawa Tengah 53127, Indonesia \\ e-mail: 1rizkiw@amikompurwokerto.ac.id, ${ }^{2}$ gilang@gmail.com
}

Informasi Artikel

Diterima: $14-12-2020$

Direvisi: 09-06-2021

Disetujui: 15-06-2021

\begin{abstract}
Abstrak
Pada Google Play Store, pengguna sering membaca review pengguna lain dan reputasi aplikasi, sebelum mengunduh sebuah aplikasi. Hal ini membuat analisis review pengguna sangat menarik bagi pemilik aplikasi untuk mengambil keputusan di masa depan. Penelitian ini bertujuan menganalisis review pengguna aplikasi Grab pada Google Play Store, menggunakan analisis sentimen. analisis review pengguna ini menggunakan metode Support Vector Machine (SVM). Evaluasi yang diusulkan dilakukan pada lebih dari 1.000 review pengguna yang dikumpulkan dari aplikasi Grab Indonesia di Google play store. Hasil dari analisis menggunakan Support Vector Machine menghasilkan akurasi 85,54\% dan Hasil Review positif yang paling sering diulas adalah "ovo", sedangkan review negatif yang paling sering diulas adalah "driver".
\end{abstract}

Kata Kunci: Text Mining, Sentiment Analysis, Support Vector Machine.

\begin{abstract}
On the Google Play Store, users often read reviews of other users and the app's reputation before downloading an app. This analyzes user reviews very interesting for app owners to make decisions in the future. This study aims to analyze grab app user reviews on the Google Play Store, using sentiment analysis. Analysis of this user review using the Support Vector Machine (SVM) method. The proposed evaluation was conducted on more than 1,000 user reviews from the Grab Indonesia app on the Google play store. The analysis results using Support Vector Machine resulted in $85.54 \%$ accuracy, and the most frequently reviewed positive Review Result was "ovo", while the most frequently reviewed negative review was "driver".
\end{abstract}

Keywords: Text Mining, Sentiment Analysis, Support Vector Machine.

\section{Pendahuluan}

Perkembangan teknologi yang sangat pesat membawa pengaruh yang besar bagi manusia. Salah satu pengaruh dari perkembangan teknologi adalah semakin maraknya penggunaan transportasi online melalui media internet. Menurut data dari riset Google, Temasek dan Bain \& Company (Google dan TEMASEK, 2018) pertumbuhan pangsa pasar transportasi online di Indonesia mengalami pertumbuhan sangat besar, pada tahun 2015 bernilai US $\$ 900$ juta meningkat di tahun 2018 sebesar US\$12,7 miliar dan di prediksi mencapai US\$ 40 miliar pada 2025. Dari riset tersebut juga menunjukan bahwa Indonesia merupakan negara dengan pertumbuhan pangsa pasar transportasi online terbesar di Asia Tenggara. Sementara itu, berdasarkan survei yang dilakukan Asosiasi Penyelenggara Jasa Internet Indonesia (APJII, 2018) memaparkan pemesanan transportasi online menempati urutan ke 16 dari 22 alasan mengapa masyarakat menggunakan internet dan $93,9 \%$ masyarakat mengakses internet menggunakan smartphone.

Terdapat beberapa transportasi online di Indonesia yaitu, Gojek, Grab, Maxim, FastGo, Bitcar, Bonceng, Anterin.id (Setyowati, 2019). Grab merupakan salah satu layanan terbesar saat ini di Indonesia (Kusnandar, 2019). Grab sebagai salah satu layanan transportasi online populer di Indonesia yang dikelola oleh Grab 
Holdings Inc yang bermarkas di Singapura. Grab didirikan pada 2012 sebagai perusahaan yang memberikan layanan transportasi. Grab kini berkembang menjadi platform seluler sesuai permintaan dan aplikasi terkemuka yang menyediakan berbagai layanan mulai dari transportasi, logistik, pembayaran, pengiriman makanan, dan berbagai layanan berdasarkan permintaan lainnya. Saat ini aplikasi Grab tersedia untuk smartphone Android dan iOS. Pengguna dapat mengunduh aplikasi secara gratis di PlayStore atau AppStore (Maruddani, 2020).

Berdasarkan data di situs google play pada tanggal 25 September 2020, Grab telah di download lebih lebih dari 100 juta kali dan memiliki rating 4,5. Pada situs google play juga tercatat 6.068.925 review pengguna di kolom komentar Grab review pengguna (Google Play, 2019). Review pengguna berisi dua bagian, yaitu nilai rating dan komentar secara tekstual. Nilai rating menunjukkan evaluasi keseluruhan pengalaman pengguna menggunakan skala numerik, namun komentar tekstual mampu bercerita lebih mendalam (Winarko, 2015). Menurut (Watrianthos dkk, 2019) review dari pengguna di PlayStore, terdiri dari review positif dan negatif seperti keluhan, kritik, atau saran.

Menurut Indrayuni (2016), analisis sentimen pada review pengguna adalah proses menyelidiki review produk di internet untuk menentukan opini atau perasaan terhadap suatu produk secara keseluruhan. Analisis sentimen adalah teknik komputasi pendapat, perasaan dan subjektivitas teks (Medhat, 2014). Tugas dasar dalam analisis sentimen adalah untuk mengklasifikasikan polaritas teks yang ada dalam dokumen, kalimat, atau pendapat. Polaritas berarti apakah teks yang ada dalam dokumen, kalimat, atau pendapat memiliki aspek positif atau negatif. Oleh karena itu, dibutuhkan suatu analisis terhadap opini-opini tersebut dalam penelitian ini agar bisa dijadikan tolak ukur baik atau tidaknya jasa transportasi online menurut pelanggan. Tujuan dari analisis sentimen adalah selain untuk mendapatkan informasi sentimen yang terkandung dalam sebuah teks, juga untuk melihat pendapat teks yang berkaitan dengan masalah atau objek, apakah itu cenderung memiliki pandangan positif atau negatif.

Analisis sentimen telah banyak digunakan dalam klasifikasi review produk. Teknik dan metode yang sering digunakan dalam analisis sentimen berbasis machine learning diantaranya Naïve Bayes, Maximum Entropy, Support Vector Machines, dan K-Nearest Neighbour. Naïve Bayes memiliki representasi yang sangat sederhana tetapi tidak memungkinkan untuk banyak hipotesis. Maximum Entropy memperkirakan distribusi probabilitas dari data, tetapi berkinerja baik dengan hanya fitur yang bergantung. SVM mungkin menyediakan kernel yang tepat, tetapi tidak memiliki cara (Borele, 2016). Banyak peneliti telah melaporkan bahwa SVM metode yang lebih akurat untuk teks klasifikasi (Hartmann, 2018). Menurut penelitian (Sharma, 2012) yang membandingkan Naïve Bayes, Support Vector Machines, Maximum Entropy, Decision Tree, K-Nearest Neighbor Classifier, Winnow Clasifier, dan Adaboost Clasifier dengan dataset review film, menghasilkan bahwa SVM menunjukkan kinerja terbaik untuk klasifikasi sentimen. SVM telah banyak digunakan dalam banyak studi klasifikasi text, salah satu kelebihannya adalah mampu mengatasi permasalahan klasifikasi teks yang bebas linear serta apabila dibandingkan dengan model machine learning lain SVM mempunyai hasil yang lebih baik dalam opinion mining (Pang, 2002) .

Penelitian ini bertujuan untuk menganalisa review pengguna pada aplikasi Grab di situs Google Play dengan menggunakan metode klasifikasi Support Vector Machine (SVM). Penggunaan Metode Support Vector Machine (SVM) dalam penelitian ini agar hasil pengklasifikasian teks Review dengan lebih baik dan akurat. Dengan hasil informasi yang lebih baik dan akurat yang diperoleh, informasi tersebut nantinya dapat dijadikan sebagai acuan dalam menjaga popularitas, kualitas pelayanan, dan dalam rangka memperbaiki kekurangan serta evaluasi ke arah yang lebih baik.

\section{Metode Penelitian}

Penelitian ini menganalisis review pengguna pada aplikasi Grab di situs Google Play menggunakan algoritme Support Vector Machines dengan tahapan penelitan yang dapat dilihat pada gambar 1 .

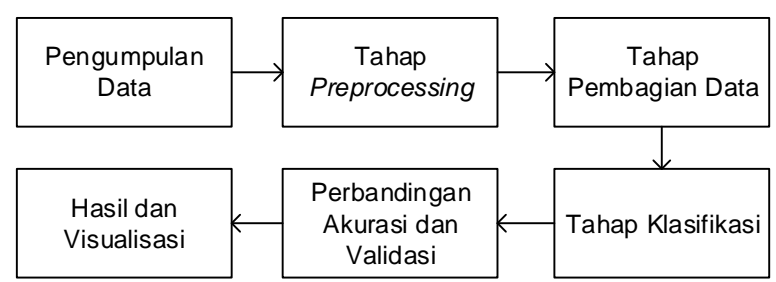

Gambar 1. Alur Penelitian

\section{a. Pengumpulan Data}

Proses pengumpulan data pada penelitian ini yaitu mengambil data primer yang diperoleh secara langsung dari sumber asli (tidak melalui media perantara) yang secara khusus dikumpulkan oleh peneliti untuk menjawab masalah penelitian (Johnson dan Gupta, 2012). Data diambil sejumlah 1000 review pengguna dengan kategori review paling relevan, karena kategori relevan menunjukan data review yang 
paling berkaitan dengan aplikasi dan dengan isi dari review pengguna yang jelas mengenai keluhan atau kepuasan dari review pengguna aplikasi Grab di situs google play dengan metode pegambilan data scraping. Untuk melakukan scraping pada penelitian ini menggunakan ekstensi di Google Chrome yaitu Scraper. Kemudian data review yang diperoleh disimpan kedalam file bertipe .csv agar data yang digunakan kedalam rapidminer pada read csv dapat terbaca dengan baik.

Pengumpulan data dilakukan dengan mengambil data review pengguna aplikasi Grab pada situs google play berbahasa Indonesia dengan alamat URL: shorturl.at/vxEHO dengan menggunakan teknik web scraping. Teknik web scraping adalah proses pengambilan sebuah dokumen semi-terstruktur dari internet, umumnya berupa laman web yang dibangun dengan bahasa markup seperti HTML atau XHTML yang bertujuan untuk mengambil informasi dari halaman tersebut baik secara keseluruhan atau sebagian untuk digunakan bagi kepentingan lain (Tripathy, 2015).

\section{b. Tahap Preprocessing}

Pada tahap preprocessing proses data yang telah diperoleh akan di olah untuk menemukan data yang diperlukan dan membuang data-data yang tidak berguna untuk tahap analisis. Data Transformasi dengan tahapan (1) Read Data, yaitu data awal yang tersimpan dalam format .csv akan diubah kedalam database rapidminer, agar data-data tersebut dapat terbaca dengan baik oleh rapidminer. (2) Case Folding, yaitu data-data tersebut akan diubah menjadi sama (lowercase). Data Cleaning dengan tahapan (1) Tokenizing, yaitu teks pada data-data yang telah diperoleh akan dipisah untuk tiap katanya. (2) Filtering, yaitu mengeliminasi kata-kata yang tidak memiliki pengaruh atau tidak informatif. (3) Spelling, yaitu perbaikan kata-kata yang memiliki kesalahan dalam penulisan atau kata yang disingkat. (4) N-gram, yaitu penghubungan kata-kata yang memiliki keterkaitan.

\section{c. Pembagian Data.}

Kumpulan kata yang dapat

mengekspresikan sentimen positif atau negatif disebut Leksion sentimen. Menurut Liu (2012), Leksikon sentimen dapat dibentuk dengan cara manual dengan cara mencari kata-kata sentimen dan mengelompokan kata sentimen menjadi sentimen positif ataupun negatif secara manual oleh peneliti. Data dibagi menjadi dua bagian dengan perbandingan $9: 1$, yaitu 9 bagian untuk data training dan 1 bagian untuk data testing. Data Training, yaitu data yang akan diolah dengan metode yang akan digunakan, yang hasilnya akan digunakan sebagai prediksi untuk data testing. Data Testing, merupakan data yang akan di uji dan diprediksi.

\section{d. Tahap Klasifikasi}

Tahap klasifikasi dengan menggunakan metode SVM, mencari hyperline (batas keputusan) terbaik yang memisahkan tiap review kedalam dua kelas yaitu review positif dan Review negatif dengan menggunakan algoritma Support Vector Machine. Dan selanjutnya data tersebut akan digunakan untuk prediksi data testing.

\section{e. Perbandingan Akurasi dan Validasi}

Proses perbandingan akurasi dan evaluasi dalam penelitian ini menggunakan kfold cross validation, dengan menggunakan nilai fold $=2 \mathrm{~s} / \mathrm{d} 10$, pengujian ini dilakukan untuk mendapatkan akurasi terbaik dalam proses pengujiannya. Dan kemudian evalusi menggunakan confusion matrix untuk mengetahui perkiraan yang benar dan salah dari hasil klasifikasi.

\section{f. Hasil}

Pada tahap ini dilakukan penarikan kesimpulan yang diperoleh berdasarkan hasil dari klasifikasi dengan menggunakan metode SVM. Serta hasil dari proses visualisasi. Penggunaan metode Support Vector Machine dalam penelitian untuk analisis sentimen review pada aplikasi Grab berdasarkan penelitian terdahulu yang telah menghasilkan kesimpulan bahwa SVM menunjukkan kinerja terbaik untuk klasifikasi analisis sentimen (Hartmann, 2018).

\section{Hasil dan Pembahasan}

\subsection{Proses scraping Metode Support Vector Machine}

Penggunaan model algoritme SVM dapat dilakukan menggunakan operator "Support Vector Machine" pada Rapidminer. Menurut penelitian terdahulu (Sharma, 2012) SVM merupakan metode yang paling bekerja baik untuk pengklasifikasian dengan dataset review. Kemampuan SVM dalam meminimalkan error data training serta meminimalkan error yang dipengaruhi oleh dimensi. SVM juga merupakan salah satu metode yang tepat untuk digunakan dalam pemecahan masalah berdimensi tinggi namun jumlah sampel data terbatas dan SVM mudah untuk diimplementasikan pada data yang telah memiliki library.

Nilai pada parameter yang dipilih untuk operator SVM merupakan nilai standar yang diberikan oleh Rapidminer. Dalam penerapan proses klasifikasi dengan menggunakan model SVM, hasil yang diperoleh dari data training selanjutnya di terapkan pada data testing. 
Selanjutnya data dihitung kembali akurasinya untuk data testing. Hasil dari akurasi terbaik dengan menggunakan metode SVM ini menghasilkan pembobotan pada tiap kata yang ada. Dari pembobotan kata tersebut digunakan pada proses klasifikasi untuk memprediksi sentimen dari data yang akan diuji. Hasil dari SVM untuk pembobotan kata. Pembobotan kata-kata ini memiliki nilai yang berbeda, jika angka pembobotan menghasilkan angka yang minus (-), maka kata tersebut dikategorikan sebagai kata negatif, sebagai contoh kata "aktif_bermasalah" dikategorikan kata negatif karena memiliki bobot nilai -0.002. tetapi jika menghasilkan angka lebih dari 0 atau tidak minus, maka kata tersebut dikategorikan sebagai kata positif, sebagai contoh "akun_aman" yang dikategorikan sebagai kata positif karena memiliki bobot 0,007 . Selanjutnya kata-kata tersebut digunakan untuk memprediksi sentimen pada data testing, hasil yang didapat seperti pada Gambar 2.

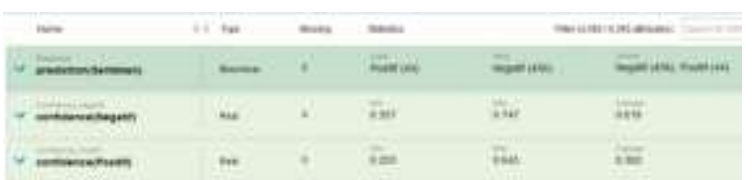

Gambar 2. Hasil Prediksi Data Testing SVM

Pada Gambar 7. merupakan hasil prediksi dari data testing. Dari 500 Review diprediksi dengan menggunakan algoritma klasifikasi SVM menghasilkan prediksi sebesar 139 Review positif dan 361 Review negatif.

\subsection{Perbandingan Akurasi dan Validasi}

\subsubsection{Perbandingan Akurasi}

Pada tahap validasi, pengujian dilakukan dengan menggunakan kedua algoritma klasifikasi dengan menggunakan cross validation, pengujian dilakukan dengan menggunakan fold=2-10. Pengujian ini bertujuan untuk mencari akurasi terbaik dari setiap algoritma. Hasil dari pengujian dari masing-masing nilai fold terdapat pada tabel 1.

Tabel 1. Hasil Pengujian Validasi dari Algoritma

\begin{tabular}{|c|c|c|}
\hline \multicolumn{3}{|c|}{ SVM } \\
\hline & Akurasi & Nilai \\
\hline fold & SVM & Kenaikan \\
\hline 2 & $84,20 \%$ & $8,23 \%$ \\
\hline 3 & $84,87 \%$ & $8,45 \%$ \\
\hline 4 & $84,21 \%$ & $7,9 \%$ \\
\hline 5 & $85,54 \%$ & $9,34 \%$ \\
\hline 6 & $84,32 \%$ & $7,79 \%$ \\
\hline 7 & $85,43 \%$ & $8,79 \%$ \\
\hline 8 & $83,76 \%$ & $7,34 \%$ \\
\hline 9 & $84,65 \%$ & $8,12 \%$ \\
\hline 10 & $84,99 \%$ & $8,57 \%$ \\
\hline
\end{tabular}

Berdasarkan Tabel 1. proses dari percobaan yang telah dilakukan dengan menggunakan metode SVM, metode SVM dengan nilai fold $=5$ akan digunakan dalam model pengujian validasi, karena pada pengujian dengan nilai fold $=5$ menunjukkan hasil akurasi yang terbaik dibandingkan dengan nilai fold yang lainnya. Hasil dari nilai fold=5 akan digunakan untuk pengujian validasi untuk metode SVM.

\subsubsection{Validasi}

Pada tahap uji validasi penelitian ini menggunakan confusion matrix dalam proses perhitungan akurasi dengan mengetahui jumlah data uji yang terklasifikasi dengan benar dan jumlah data uji yang salah dalam pengklasifikasiannya. Perbandingan confusion matrix dengan pengujian menggunakan fold $=5$ untuk SVM dapat dilihat pada Tabel 2.

Tabel 2. Confusion Matrix

\begin{tabular}{ccc}
\hline \multirow{2}{*}{ Prediksi } & \multicolumn{2}{c}{ SVM } \\
\cline { 2 - 3 } & Negatif & Positif \\
\hline Negatif & 663 & 110 \\
Positif & 20 & 106
\end{tabular}

Akurasi

$$
85,54 \%
$$

Berdasarkan Tabel 2. menggambarkan seberapa besar persentasi data yang diprediksi oleh metode SVM. True negatif merupakan banyaknya data observasi dengan kategori negatif yang mampu diprediksi negatif (diprediksi dengan tepat) oleh masing-masing metode. True positif yaitu banyaknya data observasi dengan kategori positif yang mampu diprediksi positif (diprediksi dengan tepat) oleh masing-masing metode. False negatif merupakan banyaknya data observasi yang berkategori negatif namun terdapat kesalahan prediksi. Sedangkan False positif merupakan banyaknya data observasi yang berkategori positif namun terdapat kesalahan prediksi.

SVM, diperoleh hasil prediksi bahwa pada kelas positif terdapat 216 Review positif yang diuji, terdapat 106 Review yang telah diklasifikasikan dengan benar dan terdapat kesalah prediksi sejumlah 157 Review yang masuk kedalam Review negatif. Kemudian pada Review negatif dengan total 683 yang diuji, terdapat 663 Review yang telah diklasifikasikan dengan benar sebagai Review negatif dan terdapat kesalahan prediksi sebesar 20 Review yang termasuk kedalam Review positif. Selanjutnya dari nilai confusion matrix tersebut diperoleh akurasi sebesar $85,54 \%$, terdapat 734 Review yang benar dalam pengklasifikasiannya oleh model SVM. 
Adapun proses perhitungan nilai dari akurasi dilakukan dengan menggunakan rumus Formulasi perhitungan (Gorunescu, 2011) Sehingga, untuk perhitungan nilai akurasi pada metode SVM sebagai berikut:

$$
\begin{aligned}
& \text { Accuracy }=\frac{T P+T N}{T P+F N+F P+T N} \times 100 \% \\
& \text { Accuracy }=\frac{106+663}{106+110+20+663} 100 \% \\
& \text { Accuracy }=\frac{769}{900} 100 \% \\
& \text { Accuracy }=85,54 \%
\end{aligned}
$$

Hasil dari proses klasifikasi yang dilakukan dengan menggunakan 900 review data training dan 100 review data testing dengan menggunakan fold $=5$ pada metode Support Vector Machine (SVM) diperoleh akurasi sebesar $85,54 \%$ yang menghasilkan prediksi bernilai benar dengan review positif sebesar 106 review serta Review negatif sebesar 663 review.

\subsection{Visualisasi}

Visualiasi dilakukan kepada kelas sentimen ditiap masing-masing klasifikasi. Visualisasi digunakan dengan tujuan yaitu untuk melihat informasi sentimen positif dan sentimen negatif, serta untuk mengekstraksi informasi berupa topik yang paling sering dibahas oleh pengguna Grab. Dari sekian banyak teks Review yang ada nantinya dapat diambil informasi yang dianggap paling penting. Adapun visualisasi untuk keseluruhan data yang paling sering muncul pada gambar

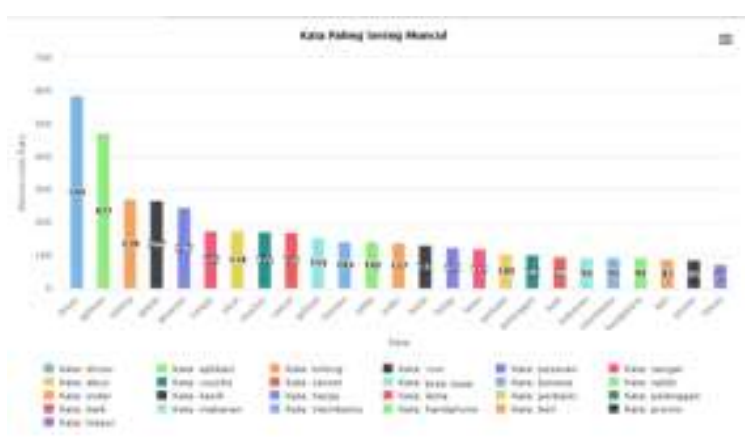

Gambar 3. Kata Yang Paling Sering Muncul Dari Keseluruhan Data

Pada proses klasifikasi yang telah dilakukan didapatkan hasil klasifikasi Review keseluruhan data sebanyak 1000 Review. Didapatkan beberapa kata yang paling sering muncul yaitu kata "driver" sebanyak 585 kali, kata "aplikasi" sebanyak 471 kali, dan kata "tolong" sebanyak 270 kali dan seterusnya.

\subsection{Review Positif}

Data Review positif yang digunakan adalah data hasil pelabelan yang dipilih secara manual dan secara nilai vector pada "kernel model" yang paling sering muncul. Dimana proses ekstraksi informasi pada Review positif dilakukan secara berulang-ulang sehingga mendapatkan informasi Review positif pengguna Grab yang paling sering dibahas. Review positif tersebut di identifikasi berdasarkan frekuensi kata dalam data Review. Visualisasi untuk data Review positif dapat dilihat Gambar 4.

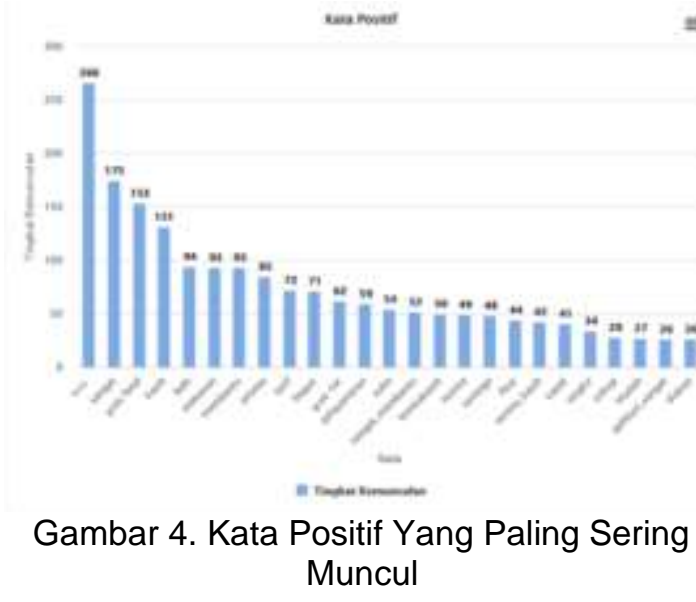

Pada Gambar 13. dapat dilihat bahwa hasil klasifikasi dari 1000 Review didapatkan beberapa kata positif yang paling sering muncul yaitu "ovo" sebanyak 266 kali, kata "sangat" sebanyak 175 kali, dan kata "grabfood" sebanyak 153 kali dan seterusnya. Kumpulan dari kata-kata yang paling sering muncul seperti pada Gambar 13. merupakan bahasan positif yang paling sering dibahas oleh pengguna Grab.

\subsection{Review Negatif}

Data Review negatif yang digunakan adalah data hasil pelabelan yang dipilih secara manual dan secara nilai vector pada "kernel model" yang paling sering muncul. Proses ekstraksi informasi pada Review negatif dilakukan secara berulang-ulang sehingga mendapatkan informasi Review negatif pengguna Grab yang paling sering dibahas. Review negatif tersebut di identifikasi berdasarkan frekuensi kata dalam data Review. Berikut visualisasi untuk data Review negatif seperti pada Gambar 5. 


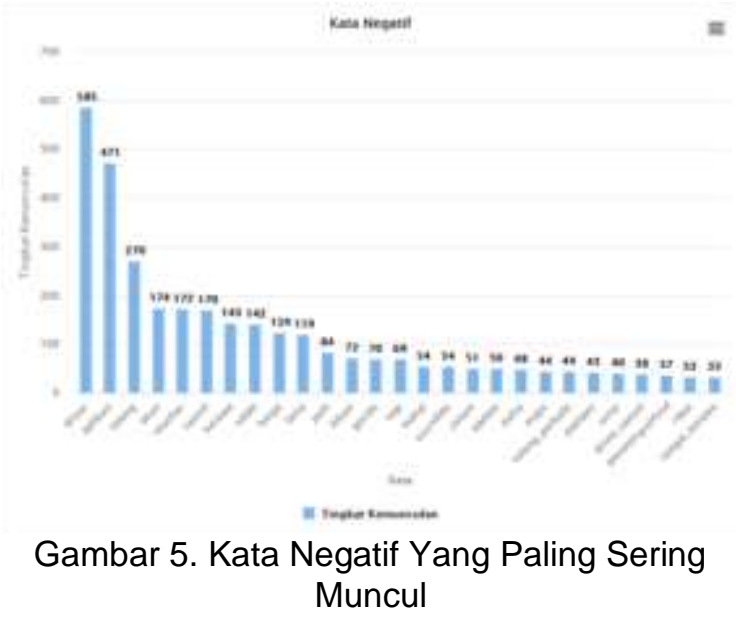

Pada Gambar 5. dapat dilihat bahwa hasil dari klasifikasi 1000 review, memperoleh beberapa kata negatif yang paling sering muncul yaitu kata "driver" sebanyak 585 kali, kata "aplikasi" sebanyak 471 kali, dan kata "tolong" sebanyak 270 kali dan seterusnya. Kumpulan dari kata-kata yang paling sering muncul seperti pada Gambar 4.32 merupakan bahasan negatif yang paling sering dibahas oleh pengguna Grab.

\subsection{Generate n-Grams}

Penggunaan generate n-grams adalah untuk mengaitkan atau menghubungkan antar kata. Penggunaan generate $\mathrm{n}$-gram dalam penelitian ini yaitu dengan length $=2$, artinya kata yang akan dihubungkan adalah 2 kata. Hasil yang didapatkan dari penghubungan 2 kata yang paling sering muncul adalah seperti pada Gambar 15.

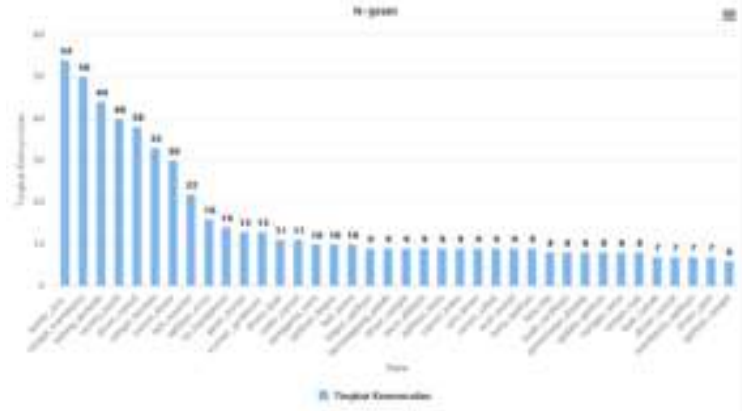

Gambar 6. Generate n-Gram ᄀPaling Sering Muncul

Pada Gambar 6. dapat dilihat bahwa hasil dari generate n--gram dari 1000 review, didapatkan kata yang paling sering muncul yaitu "saldo_ovo" sebanyak 54 kali, "sangat_membantu" sebanyak 50 kali, "tolong_perbaiki" sebanyak 44 kali dan seterusnya.

Sedangkan untuk generate n-gram dengan kategori positif yaitu seperti pada Gambar 7.

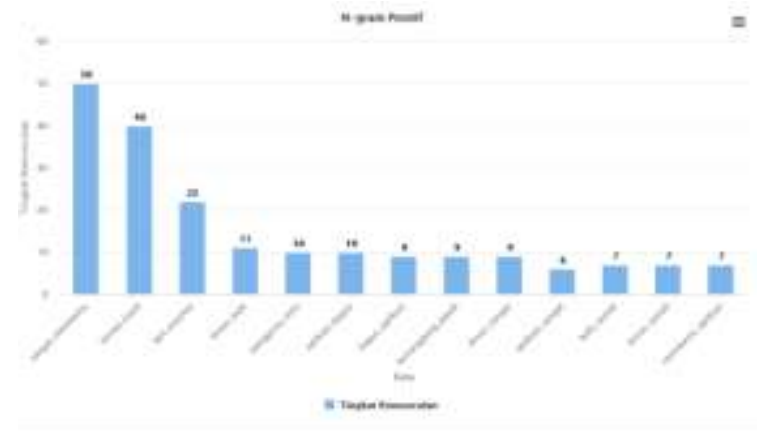

Gambar 7. Generate n-Gram Kata Positif

Dari hasil gambar 7, 2 kata yang paling sering muncul untuk kategori positif dari 1000 data Review yaitu "sangat_membantu" sebanyak 50 kali, "terima_kasih" sebanyak 40 kali, "beli_voucher" sebanyak 22 kali dan seterusnya. Dari 2 kata yang dihubungkan tersebut dapat disimpulkan bahwa aplikasi Grab telah sangat membantu dan para pengguna berterimakasih karena adanya aplikasi Grab, juga senang dengan adanya voucher dan driver yang baik dan ramah.

Selanjutnya untuk generate n-gram dengan kategori negatif yaitu sebagai berikut:

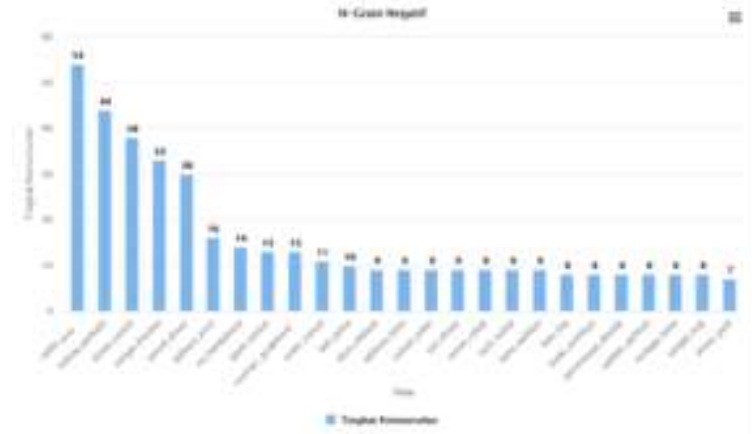

Gambar 8. Generate n-Gram Kata Negatif

Dari hasil diatas, 2 kata yang paling sering muncul untuk kategori negatif dari 1000 data Review yaitu "saldo_ovo" sebanyak 54 kali, "tolong_perbaiki" sebanyak 44 kali, "driver_cancel" sebanyak 38 kali dan seterusnya. Dari 2 kata yang dihubungkan tersebut dapat disimpulkan bahwa pengguna banyak membahas saldo ovo yang bermasalah dan banyak yang meminta untuk diperbaiki. Pengguna dari aplikasi Grab juga mengeluhkan karena driver sering membatalkan pesanan.

Hasil dari proses visualisasi memberikan informasi berupa kata yang paling sering muncul, kata Review positif yang sering muncul, kata Review negatif yang sering muncul, dan dua kombinasi kata yang paling sering muncul. Kata Review positif yang paling sering muncul yaitu kata "ovo" sebanyak 266 kali, sedangkan kata Review negatif yang sering muncul yaitu kata "driver" sebanyak 585 kali. Dan dari katakata yang paling sering muncul terdapat dua 
kombinasi dari dua kata yang sering muncul yaitu "saldo_ovo", "tolong_perbaiki", "driver_cancel" untuk dua kombinasi kata kategori negatif.

\section{Kesimpulan}

Berdasarkan hasil eksperimen yang ditampilkan pada Gambar 13. di simpulkan kata yang bernilai positif yang paling sering diulas oleh pengguna adalah tentang "ovo" yang muncul sebanyak 266 kali, sedangkan untuk kata yang bernilai negatif dapat dilihat pada Gambar 17. yang paling sering diulas oleh pengguna adalah tentang "driver" yang muncul sebanyak 585 kali, yang menandakan keluhan terhadap para driver-driver Grab. Dan dari katakata negatif yang paling sering muncul didapatkan dua kombinasi dari dua kata yang paling sering muncul bersamaan yaitu kata "saldo_ovo" dan kata "tolong_perbaiki", yang menandakan bahwa pengguna sering mengeluhkan masalah terkait saldo ovo.

Hasil dari proses analisis sentimen terhadap 900 Review data testing dengan menggunakan nilai pengujian fold $=5$ pada metode Support VectorMachine (SVM) diperoleh akurasi sebesar $85,54 \%$ yang menghasilkan prediksi pada data testing yaitu Review positif sebesar 59 Review serta Review negatif sebesar 675 Review.

Pada penelitian ini data Review yang digunakan masih dibatasi untuk Review yang berkategori paling relevan, sehingga perlu dikembangkan pada penelitian selanjutnya dengan menggunakan Review yang berkategori lainnya atau menggunakan data Review dari rentang waktu tertentu. Bagi penelitian selanjutnya, dapat menggunakan pendekatan dengan pendeteksian emoticon dengan metode Lexicon Based Approach.

\section{Ucapan Terimakasih}

Terimakasih penulis ucapkan kepada LPPM Universitas Amikom Purwokerto yang telah memberikan bantuan baik moril maupun materil sehingga penelitian ini dapat terselesaikan.

\section{Referensi}

APJII. (2018). Penetrasi \& Profil Perilaku Pengguna Internet Indonesia. Apjii, 51. Retrieved from www.apjii.or.id

Bo Pang, Lillian Lee, and Shivakumar Vaithyanathan. (2002). Thumbs up? sentiment classification using machine learning techniques. In Proceedings of the Conference on Empirical Methods in Natural Language Processing (EMNLP), pages 79-86.
Borele, P., \& Borikar, D. A. (2016). An Approach to Sentiment Analysis using Artificial Neural Network with Comparative Analysis of Different Techniques. IOSR Journal of Computer Engineering, 18(2), 2278-2661. https://doi.org/10.9790/0661-1802056469

Desy Setyowati, (2019) "Asing hingga Lokal, Ini Lima Pesaing Gojek dan Grab di Indonesia" Wired, [Online]. Tersedia https://katadata.co.id/berita/2019/08/07/asi ng-hingga-lokal-ini-lima-pesaing-gojekdan-grab-di-indonesia [Diakses: 25 Desember 2019].

Google, \& TEMASEK. (2018). Report e-Conomy SEA 2018. 1-32. Retrieved from https://www.thinkwithgoogle.com/_qs/docu ments/6730/Report_eConomy_SEA_2018 _by_Google_Temasek_v.pdf

Gorunescu, F. (2011). Data mining concepts, models, and techniques. Berlin: Acid-free paper

Hartmann, J., Huppertz, J., Schamp, C., \& Heitmann, M. (2018). Comparing automated text classification methods. International Journal of Research in Marketing.

doi:10.1016/j.ijresmar.2018.09.009

Ilmawan, Edi Winarko. (2015) Aplikasi Mobile untuk Analisis Sentimen pada Google Play. IJCCS, Vol.9, No.1. FMIPA UGM Yogyakarta.ISSN: 1978-1520.

Indrayuni, E. (2016). Analisa Sentimen Review Hotel Menggunakan Algoritma Support Vector Machine Berbasis Particle Swarm Optimization. Jurnal Evolusi Volume 4 Nomor 2 - 2016, 4(2), 20-27.

Johnson, F., \& Gupta, S. (2012). Web Content Mining Techniques: A Survey. International Journal of Computer Applications, 47(11), 44-50. https://doi.org/10.5120/7236-0266

Liu, B. (2012). Sentiment Analysis and Opinion Mining. AAAI-2011 Tutorial. https://doi.org/10.2200/S00416ED1V01Y2 01204 HLT016

Medhat, W., Hassan, A., \& Korashy, H. (2014). Sentiment analysis algorithms and applications: A survey. Ain Shams Engineering Journal, 5(4), 1093-1113. https://doi.org/10.1016/j.asej.2014.04.011

N. Fitriyah, B. Warsito, and D. A. Maruddani, 
(2020). "Analisis Sentimen Gojek Pada Media Sosial Twitter Dengan Klasifikasi Support Vector Machine (SVM)," Jurnal Gaussian, vol. 9, no. 3, pp. 376-390. https://doi.org/10.14710/j.gauss.v9i3.2893 2

Play, Google. (2019). Goole Play Store. https://play.google.com/store. Diakses pada tanggal 1 Oktober 2019.

Sharma, A., \& Dey, S. (2012). A Comparative Study of Feature Selection and Machine Learning Techniques for Sentiment Analysis. RACS'12, October 23-26, 2012. ACM 978-1-4503-1492-3/12/10.

Tripathy, A., Agrawal, A., \& Rath, S. K. (2015). Classification of Sentimental Reviews Using Machine Learning Techniques.
Procedia Computer Science, 57, 821-829. https://doi.org/10.1016/j.procs.2015.07.52 3

Viva Budy Kusnandar, (07 Agustus 2019) "Berapa Pangsa Pasar Jasa Layanan Transportasi Online Indonesia?". [Online]. Tersedia:

https://databoks.katadata.co.id/datapublis h/2019/10/05/berapa-pangsa-pasar-jasalayanan-transportasi-online-indonesia

Watrianthos, R., Suryadi, S., Irmayani, D., Nasution, M., \& Simanjorang, E. F. S. (2019). Sentiment analysis of traveloka app using naïve bayes classifier method. International Journal of Scientific and Technology Research, 8(7), 786-788. https://doi.org/10.31227/osf.io/2dbe4 